\title{
Disruption of the alsSD operon of Enterococcus faecalis impairs growth on pyruvate at low $\mathrm{pH}$
}

Correspondence
Christian Magni
magni@ibr.gov.ar

Received 15 December 2010

Revised 26 May 2011

Accepted 27 June 2011
Guillermo D. Repizo, ${ }^{1}$ Pablo Mortera ${ }^{1,2}$ and Christian Magni ${ }^{1}$

${ }^{1}$ Instituto de Biología Molecular y Celular de Rosario (IBR-CONICET) and Departamento de Microbiología, Facultad de Ciencias Bioquímicas y Farmacéuticas, Universidad Nacional de Rosario, Suipacha 531, (S2002LRK) Rosario, Argentina

${ }^{2}$ Instituto de Química Orgánica de Rosario (IQUIR-CONICET) and Departamento de Química Analítica, Facultad de Ciencias Bioquímicas y Farmacéuticas, Universidad Nacional de Rosario, Suipacha 531, (S2002LRK) Rosario, Argentina

Diacetyl and acetoin are pyruvate-derived metabolites excreted by many micro-organisms, and are important in their physiology. Although generation of these four-carbon (C4) compounds in Enterococcus faecalis is a well-documented phenotype, little is known about the gene regulation of their biosynthetic pathway and the physiological role of the pathway in this bacterium. In this work, we identified the genes involved in $\mathrm{C} 4$ compound biosynthesis in Ent. faecalis and report their transcriptional analysis. These genes are part of the als $S D$ bicistronic operon, which encodes $\alpha$-acetolactate synthase (AlsS) and $\alpha$-acetolactate decarboxylase (AlsD). Our studies showed that alsSD operon transcription levels are maximal during the exponential phase of growth, decreasing thereafter. Furthermore, we found that this transcription is enhanced upon addition of pyruvate to the growth medium. In order to study the functional role of the als $S D$ operon, an isogenic als $S D$ mutant strain was constructed. This strain lost its capacity to generate C4 compounds, confirming the role of alsSD genes in this metabolic pathway. In contrast to the wild-type strain, the als $S D$-deficient strain was unable to grow in LB medium supplemented with pyruvate at an initial $\mathrm{pH}$ of 4.5. This dramatic reduction in growth parameters for the mutant strain was simultaneously accompanied by the inability to alkalinize the internal and external medium under these conditions. In sum, these results suggest that the decarboxylation reactions related to the $\mathrm{C} 4$ biosynthetic pathway give enterococcal cells a competitive advantage during pyruvate metabolism at low $\mathrm{pH}$.

\section{INTRODUCTION}

The genus Enterococcus belongs to the lactic acid bacteria group, whose members have been traditionally used for the production of fermented foods. However, the employment of Enterococcus species in the food industry remains controversial. Enterococci are extremely versatile and well suited for survival under harsh conditions, and they have been associated with a number of human and animal infections as opportunistic pathogens. On the other hand, they are commensals, constituting the healthy microbiota of the gastrointestinal tract of humans, mammals and birds, and under most circumstances they do not cause any harm to the host (Ogier \& Serror, 2008). Although this

Abbreviations: AL, acetolactate; ALD, $\alpha$-acetolactate decarboxylase; ALS, $\alpha$-acetolactate synthase; $\mathrm{BDH}$, butanediol dehydrogenase; CDCFD, carboxy-2',7'-dichlorofluorescein diacetate; DAR, acetoin-diacetyl reductase; MU, Miller units; VP, Voges-Proskauer.

Two supplementary figures and two supplementary tables are available with the online version of this paper. genus is not considered as generally recognized as safe (GRAS), some enterococcal strains are used as probiotic agents and have beneficial effects on a number of gastrointestinal and systemic diseases (Franz et al., 2003). Moreover, they are of technological significance, since they play an important role in the ripening of cheeses, probably through proteolysis and lipolysis (Foulquié Moreno et al., 2006). Furthermore, their capacity to metabolize citrate and pyruvate is essential in the generation of four-carbon (C4) compounds, such as diacetyl, acetoin and 2,3butanediol. These compounds are involved in generating the aroma and flavour of dairy products, and contribute to improving the quality of fermented foods (Giraffa, 2003).

Pyruvate is a key catabolic compound in Enterococcus faecalis; it is the final product of glycolysis and other catabolic pathways, and may be further metabolized via several enzymes or combinations thereof, depending on environmental conditions (Fig. 1). Given the homolactic behaviour of this micro-organism, when carbohydrates are present in the medium, pyruvate is reduced primarily to 


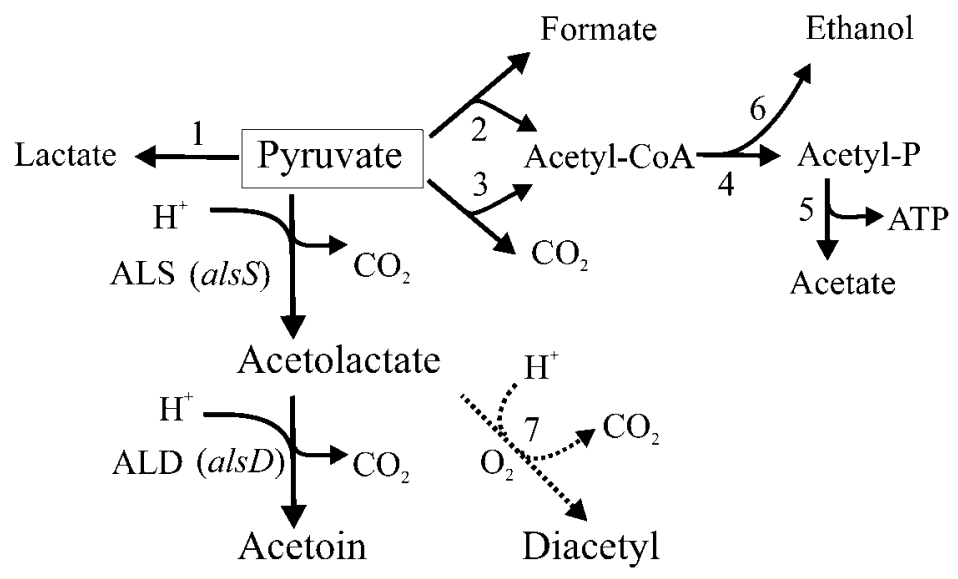

Fig. 1. Pyruvate metabolism in Ent. faecalis. Enzymes involved in the pyruvate fermentation pathway of Ent. faecalis: 1, lactate dehydrogenase; 2 , pyruvate formate lyase; 3 , pyruvate dehydrogenase; 4, phosphotransacetylase; 5, acetate kinase; 6, alcohol dehydrogenase; 7, non-enzymic oxidative decarboxylation. $\mathrm{H}^{+}$, proton scalar consumption is indicated for the ALS and ALD catalytic steps.

lactate by lactic dehydrogenase, which is activated by the glycolysis intermediate fructose 1,6-bisphosphate (Leblanc, 2006). In this manner, high levels of NADH produced during glycolysis are reoxidized and redox balance is achieved.

In addition to its role as a key intermediate, pyruvate has been identified as an energy source for Ent. faecalis growth (Deibel \& Niven, 1964). It has been previously reported that in the presence of this compound higher cell yields, external $\mathrm{pH}$ values and $\mathrm{C} 4$ compound production are obtained compared with cultures of Ent. faecalis grown in the presence of glucose. As a result of pyruvate utilization, besides lactate, significant amounts of acetate and formate are produced. The production of the last two compounds may be the result of pyruvate dehydrogenase (PDH) complex or pyruvate-formate lyase (PFL) activity (Fig. 1), both generating acetyl-CoA from pyruvate and simultaneously transforming the carboxyl group of pyruvate into $\mathrm{CO}_{2}$ (via PDH) or into formic acid (via PFL). Then, acetylCoA is converted to acetate and ATP (via phosphotransacetylase and acetate kinase) or to ethanol and $\mathrm{NAD}^{+}$(via alcohol dehydrogenase), according to the energy needs and redox state of the cell (Leblanc, 2006).

Another enzyme described in Ent. faecalis as being involved in pyruvate metabolism is $\alpha$-acetolactate synthase (ALS), which catalyses the thyamine pyrophosphate (TPP)-dependent condensation of two moles of pyruvate to give one mole of $\alpha$-acetolactate (AL). ALS constitutes the first enzyme of the C4 biosynthetic pathway (Xiao \& Xu, 2007). The apparent $K_{\mathrm{m}}$ for pyruvate of ALS in cell-free extracts of Ent. faecalis has been found to be $40 \mathrm{mM}$ (Snoep et al., 1992a), which is consistent with a $K_{\mathrm{m}}$ value of $50 \mathrm{mM}$ and a $\mathrm{pH}$ optimum of 6.0, as determined in vitro for the purified enzyme of Lactococcus lactis (Snoep et al., 1992b). As compared with the other enzymes mentioned above, ALS has a very low affinity for pyruvate, which indicates that this enzymic reaction is favoured under conditions of intracellular accumulation of pyruvate and acidic $\mathrm{pH}$. These conditions are indeed those empirically determined to be optimal for the production of C4 compounds during
L. lactis fermentation: low external $\mathrm{pH}$ due to acidic byproduct generation and co-metabolism of sugars and secondary carbon sources, such as citrate, which increase internal pyruvate concentration (Hugenholtz \& Starrenburg, 1992).

Once AL is formed, it could be converted to acetoin, mediated by $\alpha$-acetolactate decarboxylase (ALD), or to diacetyl by a non-enzymic oxidative decarboxylation step (Fig. 1). Many of the micro-organisms that express a functional C4 pathway also possess acetoin-diacetyl reductase (DAR) and butanediol dehydrogenase (BDH) enzymes. The former is involved in the irreversible reduction of diacetyl to acetoin and then to 2,3-butanediol, while the latter is capable of regenerating acetoin from 2,3-butanediol, requiring $\mathrm{NAD}^{+}$as cofactor (Xiao \& Xu, 2007).

It has been reported that $\mathrm{C} 4$ metabolism can prevent overacidification of the intracellular environment and culture medium during bacterial fermentative metabolism. This may be achieved by the conversion of pyruvate into C4 compounds and their subsequent excretion (Tsau et al., 1992; Yoon \& Mekalanos, 2006). In L. lactis, we have previously demonstrated that the genes encoding the C4 pathway are specifically induced at low $\mathrm{pH}$ at the transcriptional level, indicating that excess pyruvate is channelled towards the production of neutral compounds. The synthesis of these metabolites is relevant in maintaining internal $\mathrm{pH}$ homeostasis at low $\mathrm{pH}$ (García-Quintáns et al., 2008).

Given the ability of Ent. faecalis to utilize pyruvate as a carbon and energy source as well as to produce acetoin and diacetyl from this compound (Deibel \& Niven, 1964), it was important for us to obtain further insight into the regulation and physiological role of the C4 pathway in Ent. faecalis. In this work, we identified the genes encoding ALS (alsS) and ALD (alsD) in the Ent. faecalis genome. Our transcriptional analysis demonstrated that these genes form a single operon and that its expression in the exponential phase is enhanced by the addition of pyruvate. Finally, a strain with a disruption of the alsSD operon showed susceptibility to increasing pyruvate concentrations under 
acidic conditions, confirming the connection between this metabolic route and the mechanisms of $\mathrm{pH}$ resistance.

\section{METHODS}

Bacterial strains and growth conditions. Cultures of Ent. faecalis strain $\mathrm{JH} 2-2$ were routinely grown at $37{ }^{\circ} \mathrm{C}$ without shaking in $100 \mathrm{ml}$ sealed bottles containing $20 \mathrm{ml}$ Luria-Bertani (LB) broth (Sambrook et al., 1989), supplemented with $25 \mathrm{mM}$ glucose (LBG). Antibiotics were added when appropriate at the following concentrations: $1 \mathrm{mg}$ kanamycin $\mathrm{ml}^{-1}, 5 \mu \mathrm{g}$ tetracycline $\mathrm{ml}^{-1}$. Overnight cultures prepared in this way were used to inoculate fresh LB adjusted to different initial $\mathrm{pH}$ values, as indicated. The inocula were diluted to an initial $\mathrm{OD}_{660}$ of 0.08 . Cultures were supplemented with glucose or pyruvate (LBP) at the specified concentrations. Alternatively, Ent. faecalis was grown in a $\mathrm{pH}$-controlled fermenter (BioFlo 110, New Brunswick Scientific) in $60 \mathrm{ml} \mathrm{LB}$ broth containing $150 \mathrm{mM}$ pyruvate at $\mathrm{pH} 5.0$ or 6.5 , which was stirred slowly with a magnetic bar. The fermenter was inoculated with an overnight batch culture, as described above. Growth medium $\mathrm{pH}$ was monitored continuously, and it was maintained at a constant level by two pumps controlled by a $\mathrm{pH}$ meter and connected to flasks containing $1 \mathrm{M} \mathrm{NaOH}$ and $1 \mathrm{M}$ $\mathrm{HCl}$. Growth was monitored by measuring $\mathrm{OD}_{660}$ in a Beckman DU640 spectrophotometer.

In order to compare the growth parameters (biomass and growth rate) of wild-type and alsSD mutant strain, Ent. faecalis was also cultivated in sterile 96-well microplates (Cellstar) in a total volume of $200 \mu \mathrm{l}$ at $37^{\circ} \mathrm{C}$. Exponentially growing cultures were diluted to an initial $\mathrm{OD}_{660}$ of 0.15 in $\mathrm{LB}$ broth (at initial $\mathrm{pH}$ values of 7.0, 5.5 or 4.5 ) containing the indicated substrates (glucose or pyruvate). Once the cultures had been set up, $\mathrm{OD}_{660}$ was registered automatically every $15 \mathrm{~min}$ in a PowerWave XS (BioTek) microplate reader. Data presented are the mean values of three independent experiments in which growth curves were assayed in duplicate.

Escherichia coli strains were routinely grown aerobically at $37{ }^{\circ} \mathrm{C}$ in LB and transformed as described by Sambrook et al. (1989). Growth was monitored by measuring $\mathrm{OD}_{600}$ in a Beckman DU640 spectrophotometer. Aerobic growth was achieved by gyratory shaking at 250 r.p.m. The appropriate antibiotics $\left(100 \mu \mathrm{g}\right.$ ampicillin $\mathrm{ml}^{-1}$, $5 \mu \mathrm{g}$ tetracycline $\mathrm{ml}^{-1}$ or $30 \mu \mathrm{g}$ kanamycin $\mathrm{ml}^{-1}$ ) were included in the medium in order to select cells harbouring the different plasmids. Plates supplemented with $20 \mu \mathrm{g} \mathrm{X}-\mathrm{Gal} \mathrm{ml} \mathrm{l}^{-1}$ and $0.15 \mathrm{mM}$ IPTG were used to identify recombinant plasmids with DNA insertions that impaired $\beta$-galactosidase activity in a $\mathrm{DH} 5 \alpha$ strain.

Construction of a Pals-lacZ transcriptional fusion. A 459 bp fragment corresponding to the $5^{\prime}$ upstream region of the als $S$ gene was amplified by PCR using oligonucleotides P1 (5'-GTTTTGCTCGAATTCCAACAACTGC-3') and P2 (5'-GTCAACGAACGAATTCATCAAAAACC- $3^{\prime}$ ) (underlined sequences indicate restriction sites). The amplicon was cloned into the vector pGEM-T Easy (Promega), giving plasmid pGEMals (Table 1). Plasmid pGEMals was digested with EcoRI and the released fragment was ligated into the corresponding site of the pTCV-lac vector (Poyart \& Trieu-Cuot, 1997), giving plasmid pTCV-S (Table 1). The precise orientation of the fragment was determined by restriction analysis. This plasmid was introduced into E. coli $\mathrm{DH} 5 \alpha$, isolated from this host and then electroporated into Ent. faecalis strain $\mathrm{JH} 2-2$, as described elsewhere (Friesenegger et al., 1991). The cloned fragments were checked by the sequencing service provided by the DNA Sequencing Facility, University of Maine.

$\boldsymbol{\beta}$-Galactosidase assays. Cells carrying the Pals-lac $Z$ transcriptional fusion were grown in LBG. Overnight cultures were diluted in $\mathrm{LB}$ to $\mathrm{OD}_{660} 0.08$, and then cells were harvested at different times until the culture reached the stationary phase. Different carbon sources were added to the growth medium at defined concentrations, when indicated. $\beta$-Galactosidase activity was determined as described by Israelsen et al. (1995), except that cells were initially permeabilized by treatment with $20 \mathrm{U}$ mutanolysin $\mathrm{ml}^{-1}$ (Sigma) for $10 \mathrm{~min}$ at $37^{\circ} \mathrm{C}$.

RNA isolation and analysis. For Northern blot and primer extension analysis, total RNA from Ent. faecalis JH2-2 cells grown in LBG was isolated by a method described previously (Martín et al., 2004). RNA was checked for rRNA integrity and yield. rRNA patterns were similar in all preparations. Total RNA concentration was

Table 1. Strains and plasmids used in this study

\begin{tabular}{|c|c|c|}
\hline Strain or plasmid & Relevant characteristics* & Reference or source \\
\hline \multicolumn{3}{|l|}{$\begin{array}{l}\text { Ent. faecalis } \\
\text { strains }\end{array}$} \\
\hline $\mathrm{JH} 2-2$ & Fus $^{\mathrm{r}}$ Rif $^{\mathrm{r}}$, plasmid-free wild-type strain & Jacob \& Hobbs (1974) \\
\hline JHGR2 & $\mathrm{JH} 2-2$ isogenic derivative alsSD mutant & This study \\
\hline \multicolumn{3}{|l|}{ E. coli strains } \\
\hline $\mathrm{DH} 5 \alpha$ & $\begin{array}{l}\text { fhuA2 } \Delta(\operatorname{argF-lacZ}) U 169 \text { phoA glnV44 } \phi 80 \Delta(\text { lacZ }) \mathrm{M} 15 \text { gyrA96 recA1 relA1 endA1 } \\
\text { thi-1 hsdR17, used as an intermediate host for cloning }\end{array}$ & Hanahan (1983) \\
\hline EC101 & $\begin{array}{l}\left.\text { Kan }^{\mathrm{r}} \text {, supE thi (lacproAB) ( } \mathrm{F}^{\prime} \text { traD36 proAB lacl } \mathrm{q}^{\mathrm{q}} \mathrm{Z} \Delta \mathrm{M} 15\right) \text { repA, used as host } \\
\text { for pGh8 constructs }\end{array}$ & Law et al. (1995) \\
\hline \multicolumn{3}{|c|}{ 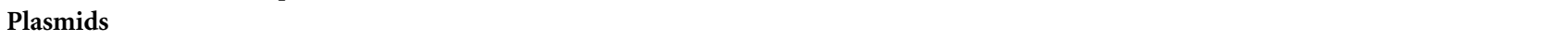 } \\
\hline pGEM-T Easy & & Promega \\
\hline pGhost8 & Thermosensitive plasmid used for insertion disruption mutagenesis in enterococci, $\operatorname{Tet}^{\mathrm{r}}$ & Maguin et al. (1996) \\
\hline pmalsS & pGh8 derivative carrying 500 bp alsS internal fragment & This study \\
\hline pGEMals & pGEM-T derivative carrying Pals promoter region & This study \\
\hline pTCV-lac & Promoterless vector which allows lac $Z$ fusion construction & Poyart \& Trieu-Cuot (1997) \\
\hline pTCV-S & pTCV-lac derivative carrying Pals promoter region & This study \\
\hline
\end{tabular}

${ }^{\star}$ Fus ${ }^{\mathrm{r}}$, fusidic acid resistance; Rif ${ }^{\mathrm{r}}$, rifampicin resistance; Tet $^{\mathrm{r}}$, tetracycline resistance. 
determined by UV spectrophotometry and gel quantification with a Gel Doc 1000 gel documentation system (Bio-Rad).

Primer extension analysis was performed as previously described (Martín et al., 2004). The primer used for detection of the start site for alsS was PrialsS (5'-CCCAAAAATATAGGGCTC-3'). A 1 pmol quantity of primer was annealed to $15 \mu \mathrm{g}$ total RNA. Primer extension reactions were performed by incubation of the annealing mixture with $200 \mathrm{U}$ Moloney murine leukaemia virus reverse transcriptase (Promega), at $42{ }^{\circ} \mathrm{C}$ for $1 \mathrm{~h}$. Determination of reaction product size was carried out in $6 \%(\mathrm{w} / \mathrm{v})$ polyacrylamide gels containing $8 \mathrm{M}$ urea by comparison with non-related sequencing ladders (Promega fmol DNA Cycle Sequencing System). Extension products were detected with a GE Healthcare Life Sciences Phosphorimager.

For Northern blot analysis, samples containing $15 \mu \mathrm{g}$ total RNA were separated in a $1.2 \%(\mathrm{w} / \mathrm{v})$ agarose gel. Nucleic acid transfer to nylon membranes and hybridization with radioactive probes were performed as previously described (Martín et al., 2004). The
alsS-hybridizing probe (probe I, Fig. 2a) was synthesized by employing the insert used for the construction of the pmalsS plasmid as template. Probes were labelled by incorporation of $\left[\alpha_{-}{ }^{32} \mathrm{P}\right] \mathrm{dATP}$ using the Prime-a-Gene Labeling System (Promega). mRNA molecular sizes were estimated by using a $0.3-6.6 \mathrm{~kb}$ RNA ladder (Promega).

Construction of an Ent. faecalis alsSD-defective strain. An alsSD-deficient strain was constructed by a single recombination event using the thermosensitive vector pGhost8 (Maguin et al., 1996). A $500 \mathrm{bp}$ internal fragment of the alsS gene was amplified by PCR using chromosomal DNA of Ent. faecalis JH2-2 as template and oligonucleotides alsS1 and alsS2. The forward primer alsS1 (5'-GCCAAAGCTTACCGTATCGCC-3') introduced an EcoRI site, while the reverse primer alsS2 (5'-CCAATTAGCTCGAATTCAGGTTGC-3') introduced a HindIII site. Underlined sequences indicate restriction sites. The PCR product was digested with the above-mentioned enzymes and ligated into the corresponding sites of the pGhost 8 vector. The resulting plasmid, named pmalsS (Table 1), was introduced into the E. coli EC101 strain, isolated from this host and then electroporated

(a)

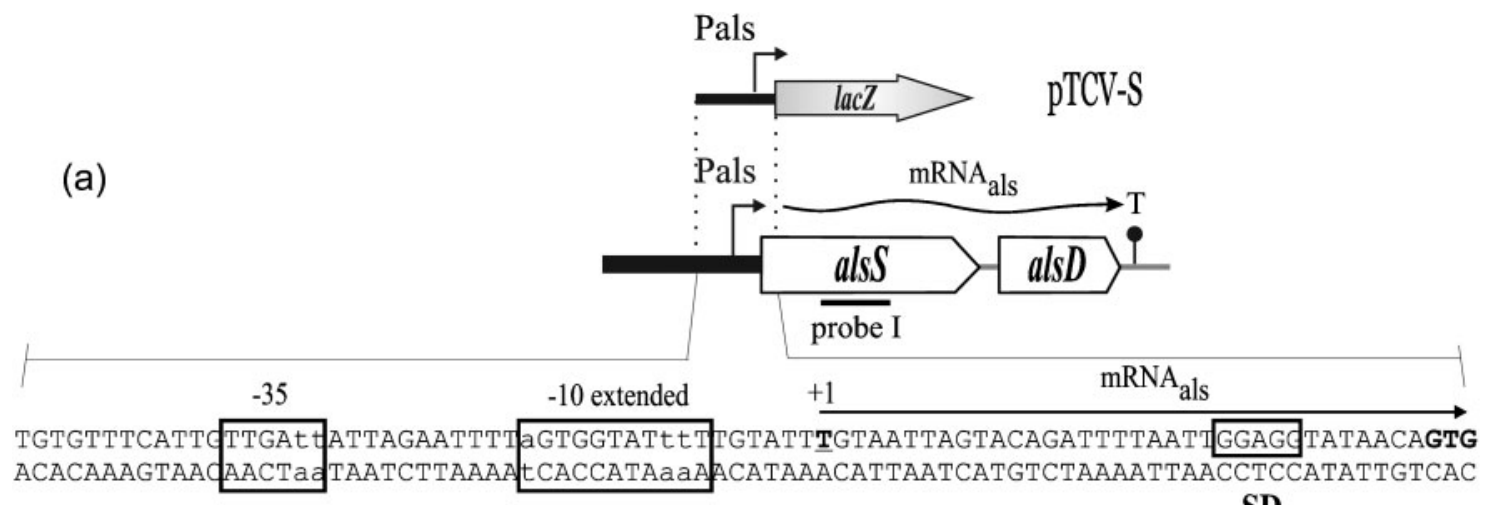

(b)

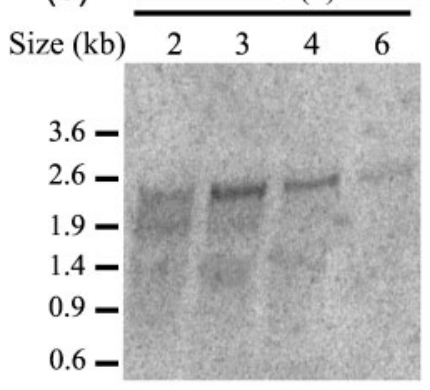

(c)

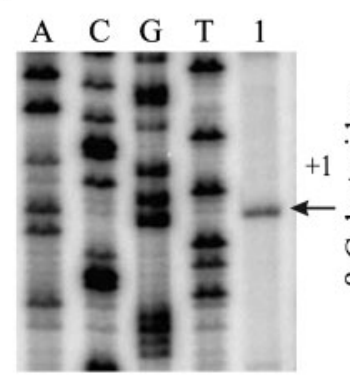

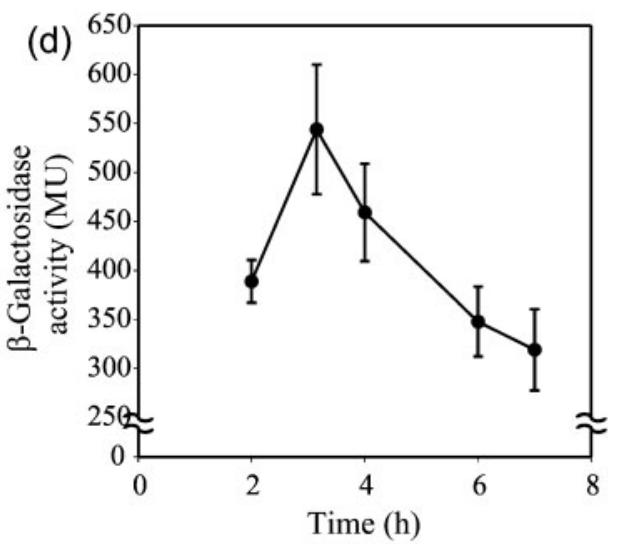

Fig. 2. Transcriptional analysis of a/sSD genes in Ent. faecalis. (a) Schematic representation of the alsSD operon. Pals, promoter region. Secondary structure, T, represents a putative Rho-independent transcriptional terminator. The nucleotide sequence of the Pals promoter region is shown below. The transcriptional start site is indicated as $+1 ;-10$ and -35 regions and the Shine-Dalgarno (SD) sequence are indicated by boxes; the translation start codon is in bold type. The Pals-lac $Z$ transcriptional fusion carried by the pTCV-S plasmid is presented above. (b) Northern blot analysis. Cells were grown in LBG, and RNA was extracted at different times $(2,3,4$ and $6 \mathrm{~h}$ ). Total RNA was hybridized against the specific probe I (see text for details). (c) Primer extension experiments for the determination of the als $S D$ transciptional start site (lane 1). Lanes A, C, G and $\mathrm{T}$ show non-related sequencing ladders. (d) $\beta$-Galactosidase activity of the Pals promoter when Ent. faecalis strain JH2-2 [pTCV-S] was grown in LBG. 
into Ent. faecalis strain $\mathrm{JH} 2-2$. Plasmid integration was induced as described by Maguin et al. (1996). Briefly, the transformant strain was grown overnight at permissive temperature $\left(30{ }^{\circ} \mathrm{C}\right)$ in $\mathrm{LBG}$ with the addition of tetracycline for plasmid maintenance. Saturated cultures were diluted 500 -fold into fresh medium and incubated at restrictive temperature $\left(37^{\circ} \mathrm{C}\right)$ for inhibition of plasmid replication. When cultures reached $\mathrm{OD}_{660} 0.5$, serial dilutions were plated on LBG with antibiotic at $37^{\circ} \mathrm{C}$. Chromosomal DNA was extracted from colonies thus obtained, and the interruption of the alsS gene was confirmed by PCR and Southern blotting. The resulting alsSD mutant strain was named JHGR2 (Table 1). It is important to note that the alsS gene interruption procedure produces a polar effect on the expression of alsD.

Quantification of C4 compounds. C4 compound (diacetyl and acetoin) concentration was determined by an adaptation of the method of Fertally \& Facklam (1987). Briefly, strains were grown in LBG or LBP medium for $6 \mathrm{~h}$ at $37^{\circ} \mathrm{C}$. Supernatant of each culture $(175 \mu \mathrm{l})$ was transferred to 96 -well microplates and $25 \mu \mathrm{l}$ of a freshly prepared solution containing $15 \%(\mathrm{w} / \mathrm{v}) \alpha$-naphthol and $0.5 \%(\mathrm{w} / \mathrm{v})$ creatine in $7.5 \mathrm{M} \mathrm{NaOH}$ was added. Once the mix was prepared, the microtitre plate was loaded into the microplate reader and $A_{540}$ was recorded every $2 \mathrm{~min}$ until it reached a constant value. The concentration of $\mathrm{C} 4$ compounds per well was calculated from the regression equation for a diacetyl standard curve. Results are presented as the mean and SD of assays performed in triplicate.

Loading of cells with the pH-sensitive fluorescent probe. Cells were first grown in batch culture in LBG medium at $\mathrm{pH}$ 7.0. The cultures were then harvested by centrifugation after reaching their exponential growth phase at $\mathrm{OD}_{660} 0.6-0.8$ and washed once with $50 \mathrm{mM}$ HEPES buffer ( $\mathrm{pH} 8.0$ ). Harvested cells were then loaded with the $\mathrm{pH}$-sensitive fluorescent probe 5-(and 6-)carboxy-2', 7 '-dichlorofluorescein diacetate (CDCFD; Biotium), as described elsewhere (Breeuwer et al., 1996). Briefly, $0.1 \mathrm{mM} \mathrm{CDCFD}$ was added to the cell suspension and incubated for $10 \mathrm{~min}$ at $30{ }^{\circ} \mathrm{C}$, and the cells were washed and resuspended in $50 \mathrm{mM}$ potassium phosphate buffer $(\mathrm{pH} 7.0)$, and finally stored in ice until use.

Internal pH measurements. For each experiment, CDCFD-loaded cells (approximately $10^{9}$ ) were suspended in $2 \mathrm{ml} 50 \mathrm{mM}$ potassium phosphate buffer, $\mathrm{pH} 4.5$, and introduced into a $3 \mathrm{ml}$ quartz cuvette ( $1 \mathrm{~cm}$ path length) equilibrated at $30{ }^{\circ} \mathrm{C}$. The sample was stirred with a magnetic stirring bar and the fluorescent signal was monitored every second in a fluorescence spectrometer (Perkin Elmer LS 55). Excitation wavelength was $490 \mathrm{~nm}$ and fluorescence emission was recorded at $525 \mathrm{~nm}$ (slit widths were $5 \mathrm{~nm}$ ). Internal $\mathrm{pH}$ was determined from the fluorescence signal, as described elsewhere (Molenaar et al., 1991). Internal and external pH was equilibrated at the end of each assay by the addition of $1 \mathrm{mM}$ valinomycin, $1 \mathrm{mM}$ nigericin and $2 \%(\mathrm{v} / \mathrm{v})$ Triton X-100. Calibration curves were determined in $50 \mathrm{mM}$ potassium phosphate buffer with $\mathrm{pH}$ values ranging from 3.0 to 11.0. $\mathrm{pH}$ was adjusted with either $\mathrm{NaOH}$ or $\mathrm{HCl}$. Experiments were performed in triplicate.

\section{RESULTS}

\section{Bioinformatic search for pyruvate-utilization genes in Ent. faecalis}

The recently available draft genomic sequence of Ent. faecalis strain JH2-2 (http://www.ncbi.nlm.nih.gov/Traces/ wgs/?val=AEBB01), also designated TX4000 (Nallapareddy et al., 2002), was searched for putative genes encoding pyruvate-utilization enzymes (Fig. 1). In this strain, genes homologous to genes encoding a classical NAD-dependent pyruvate dehydrogenase complex with an E1 $\alpha$ (EFT41959), E1 $\beta$ (EFT41958), E2 (EFT41957) and E3 (EFT41956) subunit composition typical for Gram-positive bacteria were found. Moreover, genes that might encode phosphotransacetylase (EFT41751), acetate kinase (EFT40840), pyruvate-formate lyase (EFT41268) and alcohol dehydrogenase (EFT41701) were detected, as well as the two genes (EFT40759 and EFT42481) reported to encode L-lactate dehydrogenases (Jönsson et al., 2009). Furthermore, we identified alsS (EFT41074) and budA (EFT41073) genes, which could encode proteins that convert pyruvate into $\mathrm{C} 4$ compounds. The alsS gene encodes an ALS (AlsS) of 550 amino acid residues with a calculated molecular mass of 60100 . The budA gene, which we propose to rename as als $D$, encodes a putative ALD (AlsD) of 234 amino acid residues with a calculated molecular mass of 25700 . The two ORFs are separated by a segment of only $14 \mathrm{bp}$ (Fig. 2a). Putative ribosome-binding sites for Gram-positive bacteria are located $7 \mathrm{nt}$ upstream of both ORFs. Since no other genes encoding proteins related to the $\mathrm{C} 4$ metabolic pathway were annotated in the $\mathrm{JH} 2-2$ strain genome, we looked for genes potentially encoding DAR or BDH enzymic activities. This analysis was performed employing the BLASTP tool (http://blast.ncbi.nlm.nih.gov/Blast.cgi) and using the amino acid sequences of the ButA and ButB proteins of L. lactis IL1403 as query (García-Quintáns et al., 2008). The results of this search did not allow us to detect proteins encoded in the Ent. faecalis genome with significant homology to those present in L. lactis.

\section{Transcriptional analysis of the alsSD operon}

Initial inspection of the DNA sequence of the als $S$ and alsD genes suggested the presence of a single transcriptional unit. Therefore, Northern blot experiments were performed to confirm this hypothesis. Total cellular RNA was prepared from Ent. faecalis cultures grown for $2 \mathrm{~h}$ in LBG. Next, total RNA was hybridized against an alsS-specific $524 \mathrm{bp} \alpha^{32}$ P-labelled DNA probe (Fig. 2a, probe I). Transcripts were estimated to be approximately $2.5 \mathrm{~kb}$ in size by comparison with RNA molecular markers (Fig. 2b), as described in Methods. This size is in good agreement with an alsS-alsD operon starting upstream of the alsS gene and ending in a putative Rho-independent terminator of transcription located $29 \mathrm{bp}$ downstream from the stop codon of alsD. The RNA secondary structure predicted with the mfold bioinformatic software (Mathews et al., 1999; Zuker, 2003) is the following: CCACGCCCATTCAAGTTGACTaactaGGTCAACTTGAATGGGCTTATTGCTGTTCGTCGC, with a Gibbs free energy $\left(\Delta G^{\circ}\right)$ of $-29.8 \mathrm{kcal} \mathrm{mol}^{-1}\left(-124.7 \mathrm{~kJ} \mathrm{~mol}^{-1}\right)$ (underlined letters indicate nucleotides involved in the complementary interaction; lower-case letters represent internal loops). In addition to the $2.5 \mathrm{~kb}$ transcript, an mRNA of $1.7 \mathrm{~kb}$ was detected with probe I (Fig. $2 \mathrm{~b}$, time equal to $2 \mathrm{~h}$ ), which is consistent with the size of the alsS gene alone. This could 
be the result of the larger transcript being processed during the early exponential growth phase. Consistent with this, several putative RNA secondary structures were found in the intergenic region between the two genes.

Next, a primer extension assay was performed in order to determine the transcription start site of the alsSD operon. Therefore, RNA obtained in the same way as described for the Northern blot experiment was hybridized to an oligonucleotide (PrialsS, see Methods) complementary to the alsS mRNA. The $3^{\prime}$ end of PrialsS hybridizes to a $49 \mathrm{nt}$ stretch downstream of the putative translational start. Comparison of the cDNA band synthesized from this primer with non-related DNA sequencing ladders as standards showed that transcription started at a $\mathrm{T}$ residue, $34 \mathrm{nt}$ upstream of the ATG translational start codon of the alsS gene (Fig. 2c). The promoter was situated further upstream, with a -35 (TTGAtt) and a -10 extended (aGTGGTATttT) putative box (lower-case letters represent bases that deviate from the Bacillus subtilis vegetative sigma A consensus sequence, Jarmer et al., 2001), which are separated by a correct $12 \mathrm{nt}$ spacing for RNA polymerase sigma factor binding and are located at the appropriate distance upstream of the transcriptional start site (Fig. 2a). From the transcriptional analysis, we conclude that the alsS and als $D$ genes are part of a bicistronic transcriptional unit that is transcribed from the Pals promoter located just upstream of the als $S$ coding region.

\section{Expression of the alsSD operon}

In order to further substantiate the transcriptional regulation of the als $S D$ operon, we generated a fusion construct formed by a $459 \mathrm{bp}$ fragment corresponding to the $5^{\prime}$ upstream region of the als $S$ gene and the lac $Z$ reporter gene (Fig. 2a) present in the promoterless vector pTCV-lac (Poyart \& Trieu-Cuot, 1997). Thus, the JH2-2 [pTCV-S] strain (Table 1), carrying the Pals-lacZ fusion, was grown in LBG at $\mathrm{pH} 7.0$, and $\beta$-galactosidase activity was examined during the exponential growth period. As is shown in Fig. 2(d), $\beta$-galactosidase activity was maximal after $3 \mathrm{~h}$ growth, diminishing after that time. To validate the data observed in $\beta$-galactosidase experiments, Northern blot analysis was performed. Total RNA was isolated from Ent. faecalis JH2-2 cultures grown for 2, 3, 4 and $6 \mathrm{~h}$ in LBG and hybridized against probe I (Fig. 2a). As expected, transcripts of approximately $2.5 \mathrm{~kb}$ in size were detected, with maximal RNA expression in cultures grown for $3 \mathrm{~h}$, in agreement with the results obtained by means of the transcriptional fusion to lac $Z$ (compare Fig. $2 \mathrm{~b}$ and d).

In a previous study, our group reported that L. lactis CRL264 promoters directing the transcription of genes related to the $\mathrm{C} 4$ pathway are induced at low $\mathrm{pH}$ (GarcíaQuintáns et al., 2008). An acidic induction of C4 genes has also been described for Klebsiella terrigena (Mayer et al., 1995), Staphylococcus aureus (Weinrick et al., 2004) and B. subtilis (Wilks et al., 2009). These data prompted us to analyse whether the Pals promoter of Ent. faecalis JH2-2 was also responding to medium acidification. Therefore, the JH2-2 [pTCV-S] strain was grown in LBG adjusted to initial $\mathrm{pH}$ values of 5.5 and 7.0. Although a $24 \%$ reduction in $\beta$-galactosidase levels was found at acidic $\mathrm{pH}[353 \pm 13$ Miller units (MU) for pH 5.5 versus $467 \pm 36 \mathrm{MU}$ for $\mathrm{pH}$ 7.0, after $4 \mathrm{~h}$ growth], probably due to stress conditions, we observed the same transcriptional pattern as the one observed when cultures were grown at initial neutral $\mathrm{pH}$ (data not shown). This experiment indicated that Pals is not induced under acidic conditions.

Next, we decided to analyse whether Pals was responding to the presence of different carbon sources in the medium. Glucose addition was assayed first, considering that in Bacillus anthracis (Ahn et al., 2006) and Vibrio cholerae, transcriptional activation of the $\mathrm{C} 4$ pathway by glucose has been demonstrated. Hence, the strain carrying the transcriptional fusion was grown in the presence of 50 and $150 \mathrm{mM}$ glucose, and then $\beta$-galactosidase activity was determined. As a result, we observed that the addition of glucose exerted repression (16 and $28 \%$, respectively) of Pals transcriptional activity compared with a culture of strain JH2-2 [pTCV-S] grown in LB with no addition (Table 2).

Furthermore, it has been shown for K. terrigena, B. subtilis and $V$. cholerae that the C4 pathway is transcriptionally activated by the addition of acetate to the growth medium (Kovacikova et al., 2005; Mayer et al., 1995; Turinsky et al., 2000). To investigate whether the Ent. faecalis alsSD genes were responding to the same effector, strain JH2-2 [pTCV-S] was cultivated in LB medium supplemented with $50 \mathrm{mM}$ glucose plus $50 \mathrm{mM}$ acetate, as reported for B. subtilis (Turinsky et al., 2000). Significant induction by the addition of acetate was not detected (Table 2).

Subsequently, we chose to supplement LB with $50 \mathrm{mM}$ pyruvate (LBP), taking into account its role as a substrate

Table 2. Effect of addition of different carbon sources to the growth medium on the expression of the Pals-lac $Z$ fusion carried by Ent. faecalis $\mathrm{JH} 2-2$

\begin{tabular}{|llc|}
\hline Growth medium $^{*}$ & MU $\dagger$ & I $\neq$ \\
\hline LB & $508 \pm 68$ & 1.00 \\
LBG 50 & $426 \pm 30$ & 0.84 \\
LBG 150 & $366 \pm 26$ & 0.72 \\
LBG $50+$ acetate 50 & $453 \pm 1$ & 0.89 \\
LBP 50 & $755 \pm 17$ & 1.48 \\
LBP 150 & $995 \pm 116$ & 1.96 \\
\hline
\end{tabular}

${ }^{\star}$ Cells were grown for $4 \mathrm{~h}$ in LB medium (initial $\mathrm{pH} 7.0$ ) supplemented with different carbon sources at the concentrations (mM) indicated.

$\dagger$ Results are presented as the mean \pm SD of activity measurements in triplicate. $\beta$-Galactosidase activity levels for the strain carrying the empty vector were less than $5 \mathrm{MU}$.

$\ddagger \mathrm{I}$, ratio of the MU values between a given condition and LB without an added carbon source. 
of AlsS. Interestingly, we observed a 1.48-fold induction with respect to the activities obtained for the culture in LB with no addition (Table 2). This increase in activity was dependent on pyruvate concentration, considering that the addition of $150 \mathrm{mM}$ of this compound to the growth medium provoked a 1.96 -fold increase of $\beta$-galactosidase activity levels when compared with the control culture (Table 2). These experiments showed an enhancement of Pals transcriptional activity upon addition of pyruvate to the medium, which has not been detected for the other micro-organisms studied so far.

\section{C4 compound production in Ent. faecalis}

To investigate the involvement of the alsSD operon in C4 compound production in Ent. faecalis, we interrupted this operon by single crossover chromosomal integration of plasmid pmalsS, thus generating an alsSD mutant strain (JHGR2; Table 1, Fig. 3a). In this strain, alsS is disrupted and the integration of the plasmid provokes a polar effect on the expression of alsD. In order to quantify the generation of C4 compounds in Ent. faecalis, the VogesProskauer (VP) reaction was performed in culture supernatants. The VP test is an important diagnostic assay used to assess bacterial ability to produce $\mathrm{C} 4$ compounds. Bacterial cultures producing these compounds turn red in the presence of $\alpha$-naphthol in basic medium. Thus, Ent. faecalis JH2-2 and JHGR2 strains were cultivated in LB medium ( $\mathrm{pH}$ 5.0) with the addition of $150 \mathrm{mM}$ glucose or pyruvate, and an aliquot of each culture supernatant was taken after $6 \mathrm{~h}$. A cell-free control was included in which LB supplemented with pyruvate was incubated for $6 \mathrm{~h}$ at $37{ }^{\circ} \mathrm{C}$ with subsequent determination of $\mathrm{C} 4$ compound levels. This assay showed that the wild-type strain was capable of producing $\mathrm{C} 4$ compounds, whereas the levels obtained for the JHGR2 strain supernatant were in the same range as those for the control (Fig. 3b). This observation implies that the enzymes encoded by the alsSD operon are required for C4 compound synthesis under these culture conditions. As expected, we also observed that the wild-type strain synthesized C4 compounds at higher levels when the culture medium was supplemented with pyruvate, reaching concentrations seven times higher than those observed for cultures to which glucose was added (Fig. 3b).

\section{The alsSD operon is required for growth on pyruvate at low pH}

We analysed the physiological role of the alsSD operon during pyruvate fermentation at different $\mathrm{pH}$ values. Therefore, growth of the Ent. faecalis wild-type and als $S D$ mutant strains was compared when they were grown in LB supplemented with 50 and $150 \mathrm{mM}$ glucose (as a control condition) or pyruvate at initial $\mathrm{pH}$ values of $7.0,5.5$ or 4.5. Cultures were performed in microplates over $10 \mathrm{~h}$ (see Methods) and growth parameters ( $\mu$, maximal growth rate; optical density, maximal biomass) were determined for (a)
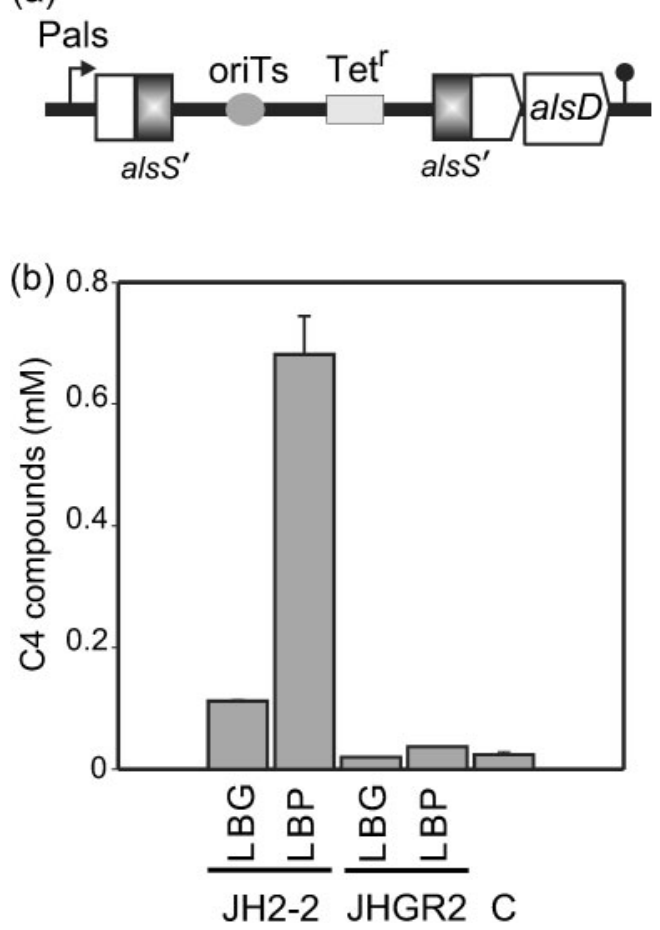

Fig. 3. Analysis of $\mathrm{C} 4$ compound production in Ent. faecalis wildtype and als $S D$-deficient strains. (a) Schematic representation of als $S$ inactivation by insertion of plasmid pmalsS. als $S^{\prime}$, fragment of the alsS gene; Tet $^{r}$, tetracycline-resistance cassette; oriTs, thermosensitive replication origin of pGhost-series plasmids (Maguin et al., 1996). (b) C4 compound titration performed on supernatants of LBG- and LBP-grown cultures of wild-type (JH2-2) and alsSD mutant (JHGR2) strains after $6 \mathrm{~h}$ growth. A cell-free control (C) was included (see text for details).

each condition. No significant differences in growth were observed between the two strains when glucose was added to the medium at any of the tested $\mathrm{pH}$ values (see Supplementary Table S1), even though a general decrease in growth parameters for both strains was detected when medium was adjusted to more acidic $\mathrm{pH}$ values. In the same way, the effect on the growth of both strains of the addition of pyruvate to the medium was evaluated. At an initial $\mathrm{pH}$ of 7.0, growth parameters for strain $\mathrm{JH} 2-2$ were similar to those for strain JHGR2 (for $150 \mathrm{mM}$ pyruvate, $\mu=0.83 \mathrm{~h}^{-1}$ versus $0.82 \mathrm{~h}^{-1}$ and $\mathrm{OD}_{660} 1.42$ versus 1.38, respectively; see Supplementary Table S2). When the $\mathrm{pH}$ of the medium was adjusted to 5.5 , the addition of $50 \mathrm{mM}$ pyruvate did not provoke any difference in growth between the two strains (compare Fig. 4a and b). However, when the amount of pyruvate was raised to $150 \mathrm{mM}, \mu$ for the wild-type strain increased to $0.75 \mathrm{~h}^{-1}\left(\mu=0.64 \mathrm{~h}^{-1}\right.$ in LB), while $\mu$ for the alsSD mutant decreased to $0.47 \mathrm{~h}^{-1}$ ( $\mu=0.63 \mathrm{~h}^{-1}$ in LB). Furthermore, biomass production for the wild-type strain was maximal under these conditions $(\mathrm{OD}=1.92)$, whereas a strong reduction was observed for the als $S D$-defective strain $(\mathrm{OD}=0.89)$ (Fig. $4 \mathrm{a}, \mathrm{b}$, 

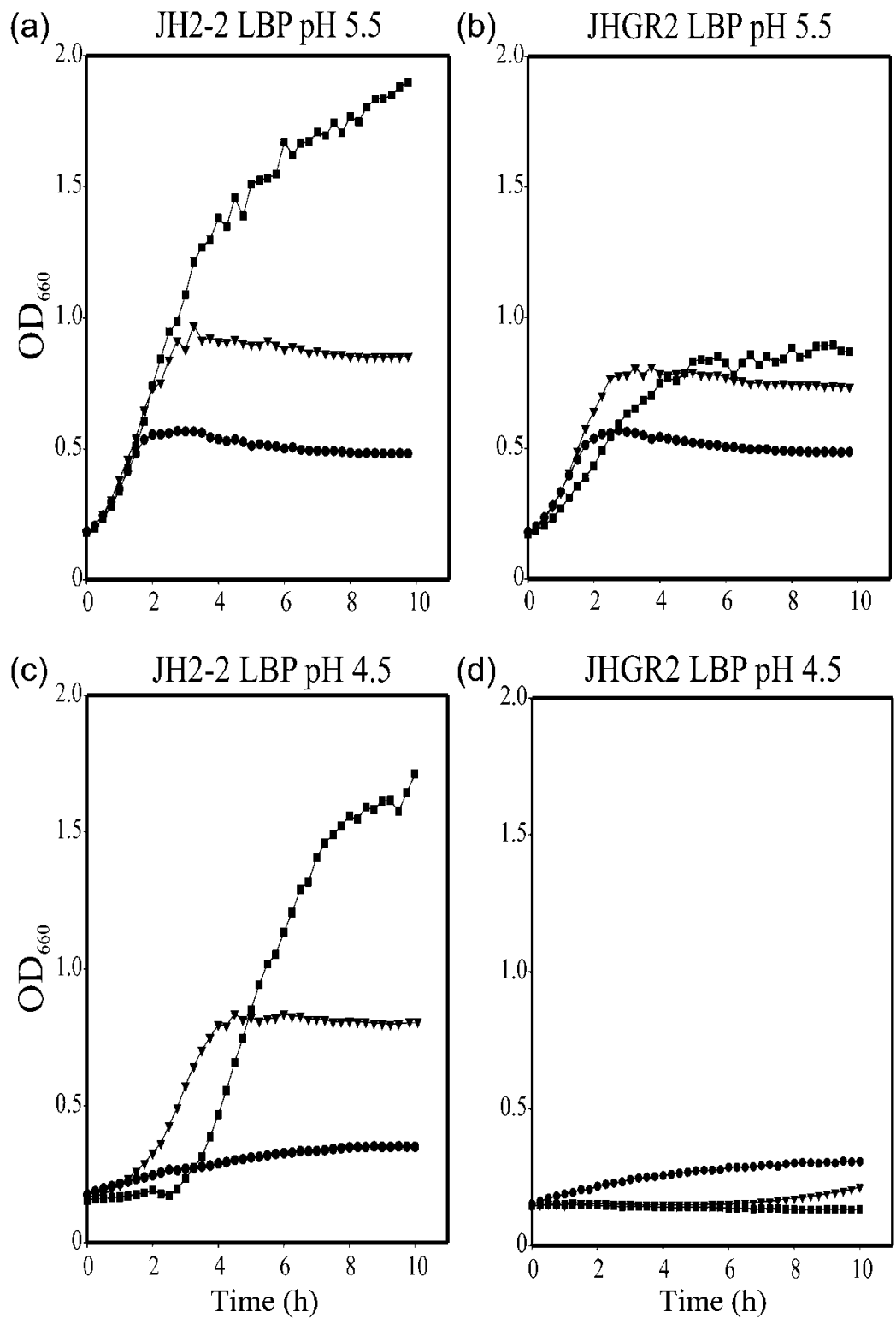

Fig. 4. Growth of Ent. faecalis $\mathrm{JH} 2-2$ and JHGR2 in LB adjusted to $\mathrm{pH} 5.5$ (a and b, respectively) or 4.5 (c and d, respectively). $\mathrm{pH}$ remained uncontrolled during the assay. Strains were grown in LB without any further carbon source addition $(\bullet)$ or were supplemented with $50(\boldsymbol{\nabla})$ or $150 \mathrm{mM}(\boldsymbol{\nabla})$ pyruvate.

Supplementary Table S2). Unquestionably, the JHGR2 strain phenotype became evident when the $\mathrm{pH}$ of the medium was set at 4.5 . Even though both the wild-type and the alsSD-deficient strain became inhibited when they were cultivated in LB without additions (Supplementary Table S2), this effect was reversed in the case of the wild-type strain when the medium was supplemented with 50 or $150 \mathrm{mM}$ pyruvate (Fig. 4c), and similar growth parameters were obtained to those observed at $\mathrm{pH} 5.5$ (Fig. $4 a)$. In contrast, these amounts of pyruvate were detrimental to the growth of strain JHGR2, which was completely inhibited (Fig. 4d). To confirm the role of the alsSD operon in this growth-deficient phenotype, we proceeded to complement the JHGR2 strain by expressing the AlsS protein in trans, using to this end the pBM01 expression vector (Marelli \& Magni, 2010). JHGR2 cells carrying the wild-type copy of the alsS gene partially recovered their capacity to grow at $\mathrm{pH} 4.5$ in the presence of $50 \mathrm{mM}$ pyruvate (Supplementary Fig. S1).

All these observations indicate that the alsSD operon fulfils an important role in pyruvate metabolism at low $\mathrm{pH}$.

\section{Comparison of external and internal pH levels between Ent. faecalis wild-type and the alsSD mutant strain}

To determine whether the observed growth impairment of the alsSD mutant was related to its inability to counteract acidification, we decided to evaluate changes in the external $\mathrm{pH}$ in batch cultures of JH2-2 and JHGR2 cells. Thus, strains were grown in LB medium supplemented with $150 \mathrm{mM}$ pyruvate at initial $\mathrm{pH}$ values of 6.5 and 5.0. As shown in Fig. 5(a), at $\mathrm{pH} 6.5$ the wild-type strain did not 
(a)

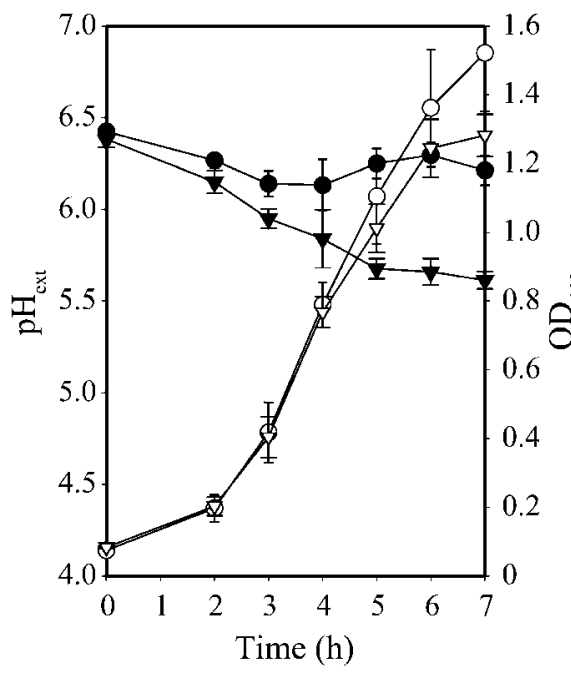

(b)

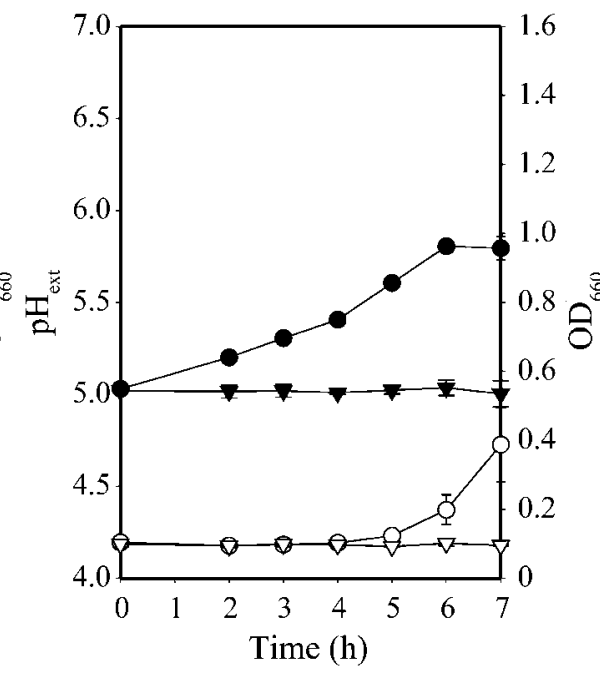

(c)

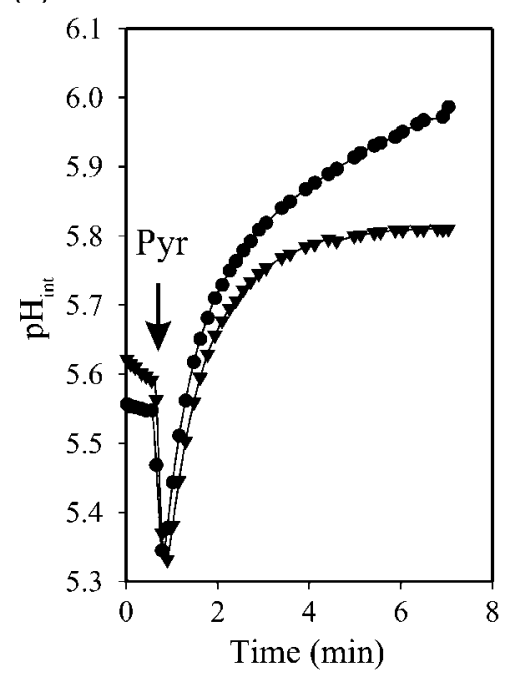

Fig. 5. External and internal $\mathrm{pH}$ variations during growth of Ent. faecalis on pyruvate. Strains JH2-2 (circles) and JHGR2 (triangles) were grown in LB supplemented with $150 \mathrm{mM}$ pyruvate at initial $\mathrm{pH}$ values of 6.5 (a) or 5.0 (b). Filled symbols, $\mathrm{pH}$ measurements; open symbols, $\mathrm{OD}_{660}$ values. Experiments were carried out in triplicate, and data are mean $\pm \mathrm{SD}$. (c) Ent. faecalis internal $\mathrm{pH}$ variations in response to pyruvate. Cells were loaded with the CDCFD fluorescent probe and suspended in phosphate buffer at $\mathrm{pH}$ 4.5. A pulse of $50 \mathrm{mM}$ pyruvate (Pyr) was added at the time indicated by the arrow.

cause a significant acidification of the growth medium, and the final $\mathrm{pH}$ value was 6.3 . Under such conditions, the $\mathrm{JH} 2-2$ strain grew to $\mathrm{OD}_{660} 1.5$ after $7 \mathrm{~h}$. On the other hand, acidification of the external $\mathrm{pH}$, reaching 5.6 after $5 \mathrm{~h}$, was observed for strain JHGR2, remaining fairly constant thereafter. This means that for the alsSD-deficient strain, the external $\mathrm{pH}$ fell 0.7 units more than for the wildtype strain. Remarkably, the als $S D$ mutant reached $O_{660}$ 1.3 after $7 \mathrm{~h}$, which is lower than the corresponding value for the wild-type.

When the initial $\mathrm{pH}$ was set to 5.0 , the $\mathrm{JH} 2-2$ strain produced an increase of 0.4 units in the external $\mathrm{pH}$ in the first $4 \mathrm{~h}$, after which growth started, reaching $\mathrm{OD}_{660} 0.4$ (Fig. 5b) after 7 h. In contrast, the JHGR2 strain was unable to alkalinize the medium and this led to growth impairment.

To continue analysing how external $\mathrm{pH}$ was affecting Ent. faecalis growth on pyruvate, cultures of wild-type and als $S D$ mutant strains were grown at a constant external $\mathrm{pH}$ of 6.5 or 5.0 in $\mathrm{LB}$ medium containing $150 \mathrm{mM}$ pyruvate. When the $\mathrm{pH}$ was set to 6.5 , both strains reached $\mathrm{OD}_{660} 2.6$ after $8 \mathrm{~h}$ (Supplementary Fig. S2a), in contrast to the results of the experiments in which external $\mathrm{pH}$ remained uncontrolled, in which a delay in growth of the alsSD mutant was detected after $4 \mathrm{~h}$ (Fig. 5a).

In contrast, when the $\mathrm{pH}$ was kept constant at 5.0, none of the strains was able to grow in the pyruvate-supplemented medium (Supplementary Fig. S2b). These results indicated that the alkalinization of the external medium observed for the wild-type strain in batch cultures (Fig. 5b), which is constrained by the fermenter, is vital for cells to start growing.

Interestingly, when after $6 \mathrm{~h}$ at constant $\mathrm{pH} 5.0$ the fermenter corresponding to the alsSD mutant strain was reset to $\mathrm{pH} 5.6$ (the value at which exponential growth of the wild-type strain in batch cultures started, Fig. 5b), the deficient strain showed an increase in optical density (Supplementary Fig. S2b).

In order to correlate these findings with intracellular $\mathrm{pH}$ changes in response to the addition of pyruvate, internal $\mathrm{H}^{+}$levels were monitored by using the $\mathrm{pH}$-sensitive fluorescent probe CDCFD. First, Ent. faecalis wild-type and als $S D$ mutant cells were grown in LBG medium adjusted to $\mathrm{pH} 7.0$ without $\mathrm{pH}$ control. Then, cells were loaded with the fluorescent probe and suspended in phosphate buffer ( $\mathrm{pH} 4.5$ ). The fluorescence measurements and their conversion to $\mathrm{pH}$ units indicated that the resting cells maintained a $\mathrm{pH}$ gradient across the membrane of about 1.1 units, more alkaline inside the bacteria, when suspended in this buffer. As shown in Fig. 5(c), addition of $50 \mathrm{mM}$ pyruvate produced an immediate cytoplasmic acidification for both strains, which was followed by a stabilization of the internal $\mathrm{pH}$ until the 3 min time point. Remarkably, after that time, the wild-type strain showed an additional increase in the internal $\mathrm{pH}$ with respect to that observed for the alsSD mutant. This alkalinization allowed the wild-type strain to reach an internal $\mathrm{pH}$ value of 6.0, while for the alsSD-deficient strain, the $\mathrm{pH}$ remained constant at 5.8. All these experiments suggest that by redirecting the accumulated pyruvate to the $\mathrm{C} 4$ pathway, 
the wild-type strain achieves a further increase in the internal $\mathrm{pH}$, which makes an extra contribution to $\mathrm{pH}$ homeostasis.

\section{DISCUSSION}

Excretion of C4 compounds, which can be determined by the VP test, has vital implications for the physiology of different micro-organisms because, as described elsewhere, it is used to avoid acidification, participates in the regulation of the NAD:NADH ratio and functions as a carbon-storing strategy (Xiao \& Xu, 2007). Although production of these compounds in Ent. faecalis has been widely used as a microbial classification marker (Fertally \& Facklam, 1987), little is known about the gene regulation of the C4 pathway and its physiological role in this bacterium. In this work, the genes involved in the biosynthesis of acetoin and diacetyl in Ent. faecalis were identified: alsS, which encodes an ALS, and alsD, which encodes an ALD. Accordingly, it was demonstrated that the disruption of alsSD genes affects the production of $\mathrm{C} 4$ compounds. No other genes encoding enzymes involved in $\mathrm{C} 4$ metabolism, such as DAR or BDH, were detected by homology searches. This is in agreement with a recent publication in which the final metabolic products from glucose and citrate metabolism were determined in Ent. faecalis V583. Under these growth conditions, production of 2,3-butanediol could not be detected (Jönsson et al., 2009).

We have also determined that the alsS and alsD genes form a bicistronic transcriptional unit directed by the Pals promoter region. Furthermore, we found that the alsSD operon is induced in the middle of the exponential phase and that its expression is enhanced by the addition of pyruvate to the culture medium. However, in Ent. faecalis no transcriptional induction of the als $S D$ genes was observed when the medium was supplemented with glucose or acetate or when the external $\mathrm{pH}$ was reduced, as has been reported for other micro-organisms (GarcíaQuintáns et al., 2008; Kovacikova et al., 2005; Mayer et al., 1995; Renna et al., 1993; Turinsky et al., 2000).

Experiments in which $\mathrm{C} 4$ compound production in the Ent. faecalis wild-type strain was quantified indicated a sevenfold increase in the concentration of these compounds in cultures grown in the presence of pyruvate with respect to those supplemented with glucose. This finding may be related to the fact that upon addition of exogenous pyruvate to the medium, it accumulates in the cell, reaching the $K_{\mathrm{m}}$ of ALS, which leads to C4 compound production. It is important to note that the transcriptional increment for the alsSD operon in response to pyruvate observed in this work could also be increasing the amount of the corresponding enzymes.

In view of these results, the role of the alsSD operon when Ent. faecalis is grown in the presence of pyruvate at different $\mathrm{pH}$ values was studied. At $\mathrm{pH}$ 7.0, strains $\mathrm{JH} 2-2$ and JHGR2 showed similar optical density and $\mu$ values for each pyruvate concentration tested (Supplementary Table $\mathrm{S} 1$ ). At this $\mathrm{pH}$, the concentration of the protonated form of pyruvate (pyruvic acid), calculated with the HendersonHasselbalch equation, is in the micromolar range (varying from 1 to $4 \mu \mathrm{M}$ when the external pyruvate concentration increases from 50 to $150 \mathrm{mM}$ ). When the external $\mathrm{pH}$ was reduced to 5.5 and $150 \mathrm{mM}$ pyruvate was added to the medium, the concentration of its protonated form increased to $0.1 \mathrm{mM}$. In this case, the wild-type strain was able to grow, whereas the alsSD-defective strain was partially inhibited (Fig. 4b). The complete arrest of strain JHGR2 occurred when the initial external $\mathrm{pH}$ value was set at 4.5 (Fig. $4 \mathrm{~d}$ ), a condition in which the external pyruvic acid concentration reaches $1.2 \mathrm{mM}$ (when $150 \mathrm{mM}$ pyruvate is added). These results showed that this 300 fold rise in the external concentration of pyruvic acid when the $\mathrm{pH}$ decreased from 7.0 to 4.5 provoked an inhibitory effect on alsSD mutant growth. We should bear in mind that the toxicity of this and other weak organic acids is related to their ability to permeate through the membrane and release protons in the more alkaline cytoplasm (Cotter \& Hill, 2003). Interestingly, this effect is efficiently counteracted by the wild-type strain through the condensation of pyruvate to $\mathrm{C} 4$ compounds.

The variation of medium $\mathrm{pH}$ during pyruvate metabolism in batch cultures of JH2-2 and JHGR2 strains also showed significant differences. When the medium $\mathrm{pH}$ was set at 6.5 , the $\mathrm{pH}$ remained fairly constant for the wild-type strain, reaching a value of 6.3 at $7 \mathrm{~h}$ of growth (Fig. 5a). Conversely, the alsSD-deficient strain showed an acidification of the external $\mathrm{pH}$ which amounted to 0.9 units after $7 \mathrm{~h}$ (Fig. 5a). Interestingly, when the initial $\mathrm{pH}$ was adjusted to 5.0, the wild-type strain showed a lag phase of $4 \mathrm{~h}$ in its growth curve during which an alkalinization of the external medium was detected (Fig. 5b). In this way, the $\mathrm{JH} 2-2$ strain resumed growth only after the external $\mathrm{pH}$ value increased by 0.4 . This may be related to the activation of other enzymic activities besides ALS that can use pyruvate as a substrate. Conversely, the alsSD mutant strain was unable to raise the medium $\mathrm{pH}$, leading to growth impairment. It has been reported that lactic acid bacteria possess numerous mechanisms to counteract acidic stress (Cotter \& Hill, 2003). However, the C4 pathway seems to be the main mechanism under the conditions employed in our study, since the wild-type strain was the only one capable of raising the external $\mathrm{pH}$ when this parameter was set initially to 5.0 (Fig. 5b). These results were corroborated by the fact that when the $\mathrm{pH}$ was kept constant at 6.5 , the alsSD-deficient strain behaved like the wild-type strain. This observation may indicate that when external $\mathrm{pH}$ remains near neutrality, pyruvateutilizing enzymes are active, pyruvate toxicity is low and the role of the C4 pathway is not as relevant as when the $\mathrm{pH}$ is more acidic.

On the other hand, when the $\mathrm{pH}$ was maintained at 5.0 during the whole assay, none of the strains was capable of growing. This may be related to the fact that the 
alkalinization provoked by the $\mathrm{C} 4$ pathway leads to $\mathrm{pH}$ values at which other pyruvate-utilizing enzymes become more active. Interestingly, when the $\mathrm{pH}$ was raised from 5.0 to 5.6, the alsSD strain resumed growth (Supplementary Fig. S2b). This observation suggests that this artificial $\mathrm{pH}$ shift replaces the external $\mathrm{pH}$ shift provoked by the $\mathrm{C} 4$ pathway in batch cultures of Ent. faecalis.

This phenomenon of growth medium alkalinization related to $\mathrm{C} 4$ compound production has also been reported for other Gram-positive and -negative micro-organisms. In $V$. cholerae and B. subtilis, it has been shown that glucose metabolism is redirected to the production of $\mathrm{C} 4 \mathrm{com}$ pounds and consequently the $\mathrm{pH}$ of the medium increases. This capacity confers an adaptive advantage that, in the case of $V$. cholerae, leads to a prolonged growth period, which has an effect on pathogenicity (Yoon \& Mekalanos, 2006), while for B. subtilis it results in a greater capacity to spread in the environment (Kinsinger et al., 2005).

In agreement with the analysis of medium $\mathrm{pH}$, our determination of internal $\mathrm{pH}$ showed that the wild-type strain has a greater capacity to alkalinize the cytoplasm in response to the addition of pyruvate at external $\mathrm{pH} 4.5$ (Fig. 5c). These observations are consistent with the fact that the enzymic reactions catalysed by AlsS and AlsD (Fig. 1) contribute to $\mathrm{pH}$ homeostasis because they result in an alkalinization of the medium caused by scalar proton consumption (Lolkema et al., 1995).

In summary, the findings obtained in this study improve our understanding of the role of the C4 pathway in Ent. faecalis, and this organism's strategies for growing on different nutrient sources and under different growth conditions. Our results show that pyruvate metabolism at low $\mathrm{pH}$ in this micro-organism requires the presence of an active C4 pathway, which can reduce the toxic levels of intracellular pyruvate while simultaneously contributing to the alkalinization of both the internal and the external medium.

\section{ACKNOWLEDGEMENTS}

This work was supported by grants from the Agencia Nacional de Promoción Científica y Tecnológica (ANPCyT; contract number 1538025, PICT 2010-1828, Argentina) and a European Union grant (BIAMFood, contract KBBE-211441). G.D.R. and P.M. are fellows from the Consejo Nacional de Investigaciones Científicas y Técnicas (Argentina), and C. M. is a member of the Researcher Career from the same institution.

\section{REFERENCES}

Ahn, J. S., Chandramohan, L., Liou, L. E. \& Bayles, K. W. (2006). Characterization of CidR-mediated regulation in Bacillus anthracis reveals a previously undetected role of S-layer proteins as murein hydrolases. Mol Microbiol 62, 1158-1169.

Breeuwer, P., Drocourt, J., Rombouts, F. M. \& Abee, T. (1996). A novel method for continuous determination of the intracellular $\mathrm{pH}$ in bacteria with the internally conjugated fluorescent probe 5 (and 6-)- carboxyfluorescein succinimidyl ester. Appl Environ Microbiol 62, 178-183.

Cotter, P. D. \& Hill, C. (2003). Surviving the acid test: responses of Gram-positive bacteria to low pH. Microbiol Mol Biol Rev 67, 429453.

Deibel, R. H. \& Niven, C. F., Jr (1964). Pyruvate fermentation by Streptococcus faecalis. J Bacteriol 88, 4-10.

Fertally, S. S. \& Facklam, R. (1987). Comparison of physiologic tests used to identify non-beta-hemolytic aerococci, enterococci, and streptococci. J Clin Microbiol 25, 1845-1850.

Foulquié Moreno, M. R., Sarantinopoulos, P., Tsakalidou, E. \& De Vuyst, L. (2006). The role and application of enterococci in food and health. Int J Food Microbiol 106, 1-24.

Franz, C. M. A. P., Stiles, M. E., Schleifer, K. H. \& Holzapfel, W. H. (2003). Enterococci in foods - a conundrum for food safety. Int $J$ Food Microbiol 88, 105-122.

Friesenegger, A., Fiedler, S., Devriese, L. A. \& Wirth, R. (1991). Genetic transformation of various species of Enterococcus by electroporation. FEMS Microbiol Lett 79, 323-328.

Garcia-Quintáns, N., Repizo, G., Martín, M., Magni, C. \& López, P. (2008). Activation of the diacetyl/acetoin pathway in Lactococcus lactis subsp. lactis bv. diacetylactis CRL264 by acidic growth. Appl Environ Microbiol 74, 1988-1996.

Giraffa, G. (2003). Functionality of enterococci in dairy products. Int J Food Microbiol 88, 215-222.

Hanahan, D. (1983). Studies on transformation of Escherichia coli with plasmids. J Mol Biol 166, 557-580.

Hugenholtz, J. \& Starrenburg, M. J. C. (1992). Diacetyl production by different strains of Lactococcus lactis subsp. lactis var. diacetylactis and Leuconostoc spp. Appl Microbiol Biotechnol 38, 17-22.

Israelsen, H., Madsen, S. M., Vrang, A., Hansen, E. B. \& Johansen, E. (1995). Cloning and partial characterization of regulated promoters from Lactococcus lactis Tn917-lacZ integrants with the new promoter probe vector, pAK80. Appl Environ Microbiol 61, 2540-2547.

Jacob, A. E. \& Hobbs, S. J. (1974). Conjugal transfer of plasmid-borne multiple antibiotic resistance in Streptococcus faecalis var. zymogenes. J Bacteriol 117, 360-372.

Jarmer, H., Larsen, T. S., Krogh, A., Saxild, H. H., Brunak, S. \& Knudsen, S. (2001). Sigma A recognition sites in the Bacillus subtilis genome. Microbiology 147, 2417-2424.

Jönsson, M., Saleihan, Z., Nes, I. F. \& Holo, H. (2009). Construction and characterization of three lactate dehydrogenase-negative Enterococcus faecalis V583 mutants. Appl Environ Microbiol 75, 4901-4903.

Kinsinger, R. F., Kearns, D. B., Hale, M. \& Fall, R. (2005). Genetic requirements for potassium ion-dependent colony spreading in Bacillus subtilis. J Bacteriol 187, 8462-8469.

Kovacikova, G., Lin, W. \& Skorupski, K. (2005). Dual regulation of genes involved in acetoin biosynthesis and motility/biofilm formation by the virulence activator AphA and the acetate-responsive LysR-type regulator AlsR in Vibrio cholerae. Mol Microbiol 57, 420-433.

Law, J., Buist, G., Haandrikman, A., Kok, J., Venema, G. \& Leenhouts, K. (1995). A system to generate chromosomal mutations in Lactococcus lactis which allows fast analysis of targeted genes. J Bacteriol 177, 7011-7018.

Leblanc, D. J. (2006). Enterococcus. In Prokaryotes, vol. 4, pp. 175204. Edited by M. Dworkin, S. Falkow, E. Rosenberg, K. Schleifer \& E. Stackenbrandt. New York: Springer Science + Business Media.

Lolkema, J. S., Poolman, B. \& Konings, W. N. (1995). Role of scalar protons in metabolic energy generation in lactic acid bacteria. J Bioenerg Biomembr 27, 467-473. 
Maguin, E., Prévost, H., Ehrlich, S. D. \& Gruss, A. (1996). Efficient insertional mutagenesis in lactococci and other Gram-positive bacteria. J Bacteriol 178, 931-935.

Marelli, B. E. \& Magni, C. (2010). A simple expression system for Lactococcus lactis and Enterococcus faecalis. J Microbiol Biotechnol 26, 999-1007.

Martín, M. G., Sender, P. D., Peirú, S., de Mendoza, D. \& Magni, C. (2004). Acid-inducible transcription of the operon encoding the citrate lyase complex of Lactococcus lactis biovar diacetylactis CRL264. $J$ Bacteriol 186, 5649-5660.

Mathews, D. H., Sabina, J., Zuker, M. \& Turner, D. H. (1999). Expanded sequence dependence of thermodynamic parameters improves prediction of RNA secondary structure. J Mol Biol 288, 911-940.

Mayer, D., Schlensog, V. \& Böck, A. (1995). Identification of the transcriptional activator controlling the butanediol fermentation pathway in Klebsiella terrigena. J Bacteriol 177, 5261-5269.

Molenaar, D., Abee, T. \& Konings, W. N. (1991). Continuous measurement of the cytoplasmic $\mathrm{pH}$ in Lactococcus lactis with a fluorescent $\mathrm{pH}$ indicator. Biochim Biophys Acta 1115, 75-83.

Nallapareddy, S. R., Duh, R. W., Singh, K. V. \& Murray, B. E. (2002). Molecular typing of selected Enterococcus faecalis isolates: pilot study using multilocus sequence typing and pulsed-field gel electrophoresis. $J$ Clin Microbiol 40, 868-876.

Ogier, J. C. \& Serror, P. (2008). Safety assessment of dairy microorganisms: the Enterococcus genus. Int J Food Microbiol 126, 291-301.

Poyart, C. \& Trieu-Cuot, P. (1997). A broad-host-range mobilizable shuttle vector for the construction of transcriptional fusions to $\beta$ galactosidase in Gram-positive bacteria. FEMS Microbiol Lett 156, 193-198.

Renna, M. C., Najimudin, N., Winik, L. R. \& Zahler, S. A. (1993). Regulation of the Bacillus subtilis alsS, alsD, and alsR genes involved in post-exponential-phase production of acetoin. J Bacteriol 175, 3863-3875.
Sambrook, J., Fritsch, E. F. \& Maniatis, T. (1989). Molecular Cloning: a Laboratory Manual, 2nd edn. Cold Spring Harbor, NY: Cold Spring Harbor Laboratory.

Snoep, J. L., de Graef, M. R., Teixeira de Mattos, M. J. \& Neijssel, O. M. (1992a). Pyruvate catabolism during transient state conditions in chemostat cultures of Enterococcus faecalis NCTC 775: importance of internal pyruvate concentrations and NADH/NAD ${ }^{+}$ratios. J Gen Microbiol 138, 2015-2020.

Snoep, J. L., Westphal, A. H., Benen, J. A., Teixeira de Mattos, M. J., Neijssel, O. M. \& de Kok, A. (1992b). Isolation and characterisation of the pyruvate dehydrogenase complex of anaerobically grown Enterococcus faecalis NCTC 775. Eur J Biochem 203, 245-250.

Tsau, J. L., Guffanti, A. A. \& Montville, T. J. (1992). Conversion of pyruvate to acetoin helps to maintain $\mathrm{pH}$ homeostasis in Lactobacillus plantarum. Appl Environ Microbiol 58, 891-894.

Turinsky, A. J., Moir-Blais, T. R., Grundy, F. J. \& Henkin, T. M. (2000). Bacillus subtilis ccpA gene mutants specifically defective in activation of acetoin biosynthesis. J Bacteriol 182, 5611-5614.

Weinrick, B., Dunman, P. M., McAleese, F., Murphy, E., Projan, S. J., Fang, Y. \& Novick, R. P. (2004). Effect of mild acid on gene expression in Staphylococcus aureus. J Bacteriol 186, 8407-8423.

Wilks, J. C., Kitko, R. D., Cleeton, S. H., Lee, G. E., Ugwu, C. S., Jones, B. D., BonDurant, S. S. \& Slonczewski, J. L. (2009). Acid and base stress and transcriptomic responses in Bacillus subtilis. Appl Environ Microbiol 75, 981-990.

Xiao, Z. \& Xu, P. (2007). Acetoin metabolism in bacteria. Crit Rev Microbiol 33, 127-140.

Yoon, S. S. \& Mekalanos, J. J. (2006). 2,3-Butanediol synthesis and the emergence of the Vibrio cholerae El Tor biotype. Infect Immun 74, 6547-6556.

Zuker, M. (2003). Mfold web server for nucleic acid folding and hybridization prediction. Nucleic Acids Res 31, 3406-3415.

Edited by: T. Abee 